\title{
Value-Free Analysis of Values: A Culture-Based Development Approach
}

\author{
Annie Tubadji \\ Economics Department, Swansea University, Bay Campus, SA1 8EN Swansea, UK; a.k.tubadji@swansea.ac.uk \\ Received: 28 October 2020; Accepted: 11 November 2020; Published: 15 November 2020 \\ check for \\ updates
}

\begin{abstract}
Recent literature in the fields of Political Economy, New Institutional Economics and New Cultural Economics has converged in the use of empirical methods, offering a series of consistent quantitative analysis of values. However, an overarching positive methodology for the value-free study of values has not yet precipitated. Building on a mixed systematic-integrative literature review of a pluralistic variety of perspectives from Adam Smith's 'Impartial' Spectator to modern moral philosophy, the current study suggests the Culture-Based Development (CBD) approach for analyzing the economic impact of values on socio-economic development. The CBD approach suggests that the value-free analysis needs: (i) to use positive methods to classify a value as local or universal; (ii) to examine the existence of what is termed the Aristotelian Kuznets curve of values (i.e., to test for the presence of an inflection point in the economic impact from the particular value) and (iii) to account for Platonian cultural relativity (i.e., the cultural embeddedness expressed in the geographic nestedness of the empirical data about values). The paper details the theoretical and methodological cornerstones underpinning the proposed CBD approach for value-free analysis of values.
\end{abstract}

Keywords: values; Aristotelian Kuznets Curve; Platonian cultural relativity; value-free analysis; Culture-Based Development

\section{Introduction}

Can economics identify which local cultural attitudes are universally valuable for the economic systems? A system that depends on value judgements cannot be adequately studied without including values as a factor for the operation of the system. Yet, a scientific study of values should be objective, without deterministic subjective labelling of values as good or bad. The current study suggests these two criteria can be met by following the Culture-Based Development (CBD) approach, which proposes that the universality of a value should be positively analyzed against its objective effect on a socio-economic output of interest.

The question about the importance of values for the existence of economies and society has been an integral part of science since its very dawn. Providing a comprehensive summary of the literature would therefore be always incomplete. The essence of the novel mixed method of literature review used here entails two steps: (i) a systematic literature review covering contributions from 1677 till 2020 on economic thought on values, culture, wellbeing and welfare and earlier philosophical contributions that this economic research built on (reviewing material mainly from Jstor, Web of Science, Google Scholar and Science Direct); and then (ii) an integrative literature review that synthesizes and recombines main perspectives from part one, in order to create a new theoretical model (of value free analysis of values). The second part is what is reported in the paper, but the first part ensures that the review is non-biased $[1,2]$. Thus, this paper conducts a mixed method of systematic-integrative literature review and outlines several cornerstones in the literature of particular importance to economics as a field and fundamental for the here proposed specific CBD approach for the value-free analysis of values. 
Modern moral philosophy, propelled by Sen and Nussbaum's research, calls for a return to the question of values in studying the factors for economic development [3-9]. Revisiting the argonauts of philosophy and sciences, Plato, and his student Aristotle, we choose to highlight here two main concepts, which are very compatible with each other. Plato (Republic $375 \mathrm{BC}$ ) is known for his parable of the cave, suggesting that cultural relativity of values exists due to the individual's local bias in the perception of the pure truth. Pure truth is presented by the parable as a flame and one's perception of pure truth is equivalent to only the reflection of this flame on the walls of one's own 'cave' (i.e., one's context). Aristotle (Nicomachean Ethics 350 BCE) suggested that a 'golden mean' of every value exists. Put differently, too much or too little affinity towards a particular value never leads to the most optimal behavior. Instead, an individual needs to empirically find out where the most-useful (i.e., 'golden') mean level of affinity to a value should be placed in order to live a really good life. Next, the father of economics as a moral philosophy, Adam Smith [10], suggested his own theory of moral sentiments, relying to a big extent on the notion of the 'Impartial' Spectator. In line with work by Khalil [11], the latter notion is interpreted in this study as the presence of a socially prescribed and internally monitored value system, which is in essence the outline of the cultural cave in which we are embedded. These three classical approaches to studying values have been deserted in neoclassical economics for decades.

In the 1930s, the urge for a value-free study of economics was suggested by neoclassical economists [12,13]. It was argued that utility and culture are difficult to measure and explain. It was hoped that a study of the economy as a system, operating on certain value-free mechanisms, could help reveal these mechanisms and put them in service for socio-economic recovery and development [14]. It was however, soon realized that it is impossible to mechanically separate culture from the economic mechanisms. Signals for this problem started being powerfully sent by important contributions to the new economic academic world $[15,16]$. The work by Herbert Simon, Tibor Scitovsky, Daniel Kahneman has pointed to the cultural- and value-dependence of the macro economics of place development and micro economics of customer behavior [17-19]. Yet, the cultural economics field became too diverse and internally disintegrated, and remained mostly apocrypha and muted in the majority of its contributions, ultimately evolving into a misperception that there needs to be necessarily some deep methodological divide between neoclassical and institutional (cultural) economics.

It was only in recent years that New Institutional Economics (NIE) realized and started promoting the alternative more natural thesis-that actually using a common methodological ground might be the key to ameliorating the general economic field and its understanding of culture and values.

New Institutional Economics (NIE) revolutionalized the field of institutional economics by opening its doors in a pluralistic manner to the use of empirical methods. NIE promoted the quantitative study of institutions and culture [20]. Studies building on this literature have empirically demonstrated that there is persistence and path-dependence in the process of impact by cultural institutions on socio-economic development [21]. Working on a very similar vein, one of the fathers of modern Political Economy, Alesina and Perotti [22], demonstrate how empirical neoclassical models can accommodate for the study of the impact by political and voting behavior on the economic process. The entire field of New Cultural Economics (NCE) has also generated numerous elaborate empirical studies demonstrating the various effects of cultural variables on various economic processes [23,24]. Alesina, Miano and Stancheva [25] also discuss the endogeneity of values and beliefs.

Yet, among all these institutional and neoclassical value-related empirical studies, no systematic positive methodology for value-free analysis of values has precipitated. The study of values needs to rely on a comprehensive methodology which can allow to the field of political economy to achieve economic synthesis on the basis of the accumulated empirical evidence. Only at the presence of a clear methodology, the economic meaning of the various empirical studies of values can be clearly comparably analyzed. The current study aims at proposing such a methodology, stemming from the CBD paradigm. 
CBD is a research paradigm which defines development as a process that depends on economic decisions which are inevitably culturally embedded and biased. In this study, CBD suggests a systematic approach to value-free study of any value in three steps through: (i) establishing whether the value has a universal impact across space, (ii) detecting if its impact exhibits nonlinearities (such as Aristotle's golden mean suggests) and (iii) explaining through Platonian cultural relativity how the universality of moral values and the presence of diverse local culturally dependent ethics can find a coherent conceptual and empirical explanation.

The paper is structured as follows: Section 2 provides an overview of the main literature that underpins the CBD value-free analysis of values approach. Section 3 describes the main conceptual postulates of this CBD approach. Section 4 explains the proposed methodological rationale. Finally, Section 5 offers some concluding remarks and comments on further operationalizations of the CBD approach in the field of economic study of values.

\section{Modern Moral Philosophy and Value-Free Analysis of Values}

Amartya Sen and Martha Nussbaum claimed recently that economics needs to reconcile with moral philosophy again [3-9,26-29]. But what is moral philosophy and why has it been disregarded as a central pillar in mainstream economics? The position of this paper is that Sen's and Nussbaum's plea is very timely but it has to and can be implemented meaningfully not through a return to old moral philosophy approaches, but through devising a modern methodological approach that seeks to find out the universal natural value by finding the universal mean of values that are observed as predominant across societies. The approach proposed here is also substantially different from the classical positivistic school approach [30-34]. The CBD approach defines the observed mean as the contemporaneously enacted morality of the contemporary world, which is only one of many possible worlds, and not necessarily the natural universal human morality, the need for which transcends time and space. Moreover, local culture is not simply the sum of the present individual attitudes, but is also weighted for the power of the groups holding certain attitudes, thus ensuring a positive value-free analysis of the 'universality' of values and attitudes

The distinction between attitudes, values, ethics and morals here is adopted in line with the following operational definitions which sum up the state of the art on these notions as understood by the author of the current study. Attitudes are modes of thinking. The level of positive affinity (passion) that we experience with regard to an attitude is the level to which we value it and determines how strongly it acts as our value. Some values enjoy high affinity among localities or groups of people-such values are called ethics of the locality or group. Ethics is usually thought of as professional ethics but is generalizable to any group valuation of attitudes, which in neo-Weberian way can be understood as local culture. Local culture is the set of attitudes the local population has strongest affinities for. Therefore, local culture can be perceived as local ethics. Finally, observed human moral is the set of attitudes for which all human beings have a strong affinity in comparison to all other attitudes. In this sense, there is a universal set of values shaping a universal moral, which is shared by all people around the world. Morality is part of human needs and we have a natural drive for seeking truly moral behavior. Yet, the absolute natural moral, just like truth, is aspired, but not fully known to any human being or group of people in any point of time and space. People may only have different level of intuition as to what the absolute moral holds. The quality of this intuition depends on their unique level of inborn ability, their achieved level of knowledge, and the socially constructed experience that they have had. Thus, intuition varies strongly across individuals even within the same cultural background [35].

In his Theory of Moral Sentiments (TMS) [10], Adam Smith defines moral philosophy as a study of the system of the modes of thinking that are of value (a study of virtues) which affect the decision making process and behavior of people. In this moral philosophy study, he then outlines two main sub-questions: (i) what is virtuous and (ii) what are the mechanisms (i.e., in Smith's words the 'principles' of the 'mind') by which virtues affect choice (i.e., the ways certain values become 
'recommended to us' as the virtues and character which we aspire to demonstrate through our choice). The answer to the first revolves around the construction of an 'Impartial' Spectator'-i.e., an objective moral code-within us, against which we measure the choices of the world and ourselves. The answer to the second sub-question is feasible to find, in Smith's understanding, since there exist universal natural mechanisms ('principles') which repeat across different cultural systems and this guarantees the objectivity of the 'Impartial' Spectator [10] (pp. 315-316). However, in line with Sen's thinking [26], the objectivity of this 'Impartial' Spectator and his ability to be universally moral has been questioned due to his dependence on man-made cultural values.

Values are subjective (unique for every individual [36]) and relative (varying across cultures as perception what is virtuous [37]). These subjectivity and relativity of values have been the apple of discord between moral philosophy and value-free economics since the early dawn of the study of economics [12,38-40]. What is defined as good and bad is inevitably a cultural artefact of its time and place [41-43]. Gaining this understanding, although it started as a moral philosophy in its old welfare economics state, the economic discipline shifted towards a completely value-free study of economic systems, partially also in order to secure its place among the rest of the academic disciplines. This was soon realized as too high a price for the status of a science among sciences as it was skipping to analyze a crucially important factor of choice-values [18,44-46]. But mainstream economics pursued its completely value-free course for a long while, completely ignoring the role of psychology and even more so of attitudes, values and culture. It took decades until the NCE, starting its dawn with Douglas North's work on institutions [47-50] and Kahneman's work on psychology in economic choice [51] (for which comprehensive reviews can be found [52]). These seminal works led to a wave of modern contributions on evidence of the impact from culture on economic development that married again the study of values with the mainstream economic discipline, establishing the field of NCE [24,53-61]. The focus of these studies has, however, remained primarily on what Smith outlined as the second key issue of moral philosophy; namely, exploring the mechanisms through which cultural values might affect economic outputs. The first sub-question posed by Smith in front of moral philosophy-as to which values are virtuous indeed-remains unanswered.

Sen and Nussbaum's claim regards exactly this empty niche in modern economics and NCE specifically. They point out that understanding merely the efficiency of economic choices and economic systems (even under the impact of values) might not be enough to contribute to understanding how to achieve a flourishing human society. Sen and Nussbaum's take agrees with what Smith who depicts the rational essence of the moral system as a function of sympathy. Namely, we read in Smith: "Of all the calamities to which the condition of mortality exposes mankind, the loss of reason appears, to those who have the least spark of humanity, by far the most dreadful, and they behold that last stage of human wretchedness with deeper commiseration than any other. But the poor wretch, who is in it, laughs and sings perhaps, and is altogether insensible of his own misery. The anguish which humanity feels, therefore, at the sight of such an object, cannot be the reflection of any sentiment of the sufferer. The compassion of the spectator must arise altogether from the consideration of what he himself would feel if he was reduced to the same unhappy situation, and, what perhaps is impossible, was at the same time able to regard it with his present reason and judgment.", [10] (p. 17). According to Sen and Nussbaum's capabilities approach, the list of capabilities that are virtuous or that at least guarantee elementary human dignity should be the aim of economic decision making for the betterment of human life and not merely for securing a more efficient economic system for its own sake [62]. While this claim is clearly contemporarily morally and sentimentally appealing, it still stumbles on its way to universality over the same criticism that Smith's 'Impartial' Spectator has been subject to. Namely, even in Smith's own words, every human moral code is 'derived from a partial and imperfect view of nature', therefore our mind and our 'Impartial' Spectators are always subjective. This fact has been recognized by Smith himself in many places in TMS in great detail when describing the role of physical/social proximity such as in the Little Finger example and his dwellings on economic relativity (such as relative wage/richness) and custom (in Part I and Part V in TMS [10]). Therefore, defining 
prescriptively our subjectively defined virtues and/or a set of desirable capabilities cannot be the answer to Smith's first sub-question in moral philosophy. Namely, Sen [27-29] seems repeatedly to claim that our moral judgement should remain always subjective by accentuating the importance of freedom of choice in his capabilities approach. Yet, just allowing for freedom in the definition of what is virtuous or universally valuable means that it will remain unclear how to precisely answer Smith's first sub-question in moral philosophy in a consistent accurate manner [63]. As noted by Kant in his 'Critique of Pure Reason': "We may certainly collect from phenomena a law, according to which this or that usually happens, but the element of necessity is not to be found in it" [64]. The CBD approach agrees with this particular statement for the following reasons. Even if we had a full data record of the evolution of the perceptions of good and bad since we were in existence as species, all we can positively empirically learn from this is what is most probable that people tended to choose as good and as bad over the centuries. Yet, this still leaves us without an objective qualitative reference point to know whether the world has always been right or wrong in its perceptions of what is good and bad. Meanwhile, what is accepted as moral changes over time is usually based on some dichotomy, thus things previously accepted as moral become considered amoral over time. Consequently, the positive search for probable correct moral is trapped in circular causality and reaffirming the past without really knowing what the perception of good and bad really has to be in order to be correct and true. How to appease, then, the lack of knowledge on what is true virtue with the need to device a moral philosophical base for policy making which is in need of prescriptive and not only descriptive studies of the economic system and values? In other words, how can a value-free study of virtues and values be devised, so that universal values are identified positively, outside the biases of the scientists' 'Impartial' Spectators-i.e., the scientist's own subjectivity and relativity of values? This problem has also been widely recognized in sociology and anthropology, which consider the study of human beings by human beings as a main challenge in front of the objectivity of the scientific analysis in social and human sciences $[65,66]$.

It is proposed here to heed Sen's and Nussbaum's advice for a return to moral philosophy but through a new methodological take. Namely, by applying the CBD approach for studying the impact of cultural values on economic choice in a positive value-free method for the analysis of values.

\section{Theoretical Motivation of the CBD Value-Free Analysis of Values}

\subsection{The Economic History of Values-A CBD Reading}

CBD builds its approach on the neo-Weberian understanding that 'values' are modes of thinking (i.e., locally highly praised attitudes) which are crucial determinants in the production function (or in the economic choice function more broadly). CBD recognizes that, nowadays, the leading economic school on culture and economics is the NCE, which explores in a quantitative manner the impact by institutions and cultural biases on a variety of economic choices [24,61]. However, the roots of the study of culture and values in economic choice extends to the very roots of the origin of economics as a moral philosophy and of philosophy as a science of the meaning of life [6], present also in relevant other disciplines such as geography and the study of space as a factor for local development. Specifically, CBD identifies four turning points in the development of the history of economic thought on values and culture that need to be revisited in order for modern cultural economics to reunited with the lost important aspects from the study of values and culture in economics.

First, CBD reminds us that culture is not only a source of cognitive bias. Nowadays, the cognitive biases are well studied and acknowledged in economic analysis due to prominent works by leading figures such as Thaler and Sunstein [67] and Kahneman [19] and the corresponding streams of literature. These studies continue the work of Simon [17] and Scitovsky [18], which were trying to reintroduce values in the study of economic choice. The reminder that culture and values cause biases was necessary to be done, because the era of Robbins' critique [12] had proposed the value-free study of economics, since values and utility had been found to be difficult to measure and compare between individuals 
and between places [68]. The work of the above-mentioned cognitive-bias and consumer behavior schools demonstrated that completely neglecting the differences in individual utilities was producing underspecified economic models [69]. Yet, while culture has a strong impact on psychological channels biasing economic choice, culture is clearly much more than a cognitive bias. Cultural values are the source of building of the local informal and formal institutions, which have a role much bigger than being a source of cognition-institutions define the socio-economic structure and the 'objective' rules of the game. Thus, certain biased valuation between categories becomes a structurally embedded norm that perpetuates different inequalities across groups over time [70].

Second, CBD reminds us that culture defines both the structure of an economic system and the target for maximizing and optimization in an economic system. What is only culturally accepted is an informal institution, and only what is weakly culturally determined needs formal institutions to reinforce the cultural preferences of the majority $[47,48]$. Thus, culture defines the structure of institutions in which the economic system operates and the economic institutions themselves differ according to the cultural attitudes, as proposed by Max Weber [71] and his claim that local attitudes derive locally specific forms of capitalism. Moreover, it was again during the Robbins' critique that the target for the economic system was established to be: optimizing the use of resources which later evolved into the idea for generating more growth. This target was chosen in a between-wars historic period when there was so much poverty that it was generally acceptable that if the economy produces more, there will be more to redistribute. This gave reason to neglecting for the moment the question how it is fair to redistribute. Clearly, however, our problems with redistributing equally, in the spirit of the Enlightenment, cannot be considered satisfactorily abolished as a relevant question by this turn in the history of economic thought [72,73]. The reason for this is not only the moral need for equality, but also the practicality of the fact that inequality leads to the collapse of any system (or 'empire') [70,74-79].

Third, CBD reminds us that culture defines what is a 'good' target for maximizing, not only by the power of reason, but also by the power of the sentiment (affinity). The utilitarian school and the Scottish Enlightenment insisted on understanding what is fair and good distribution of resources. These were times when moral philosophy was trying to define the good for the society target and was not concerned with the productivity alone. The reason for this was the link between economics and the mother of all sciences-philosophy, which had long tried to define the good life. Economics had set on the path of ensuring the resources which are necessary in order to achieve the good life and therefore the definition of good life was attempted to be clarified [80]. Indeed, in the Age of Reason, Spinoza [81] and others attempt to draw a clear line between (i) reason and (ii) the affect (sentiment) and imagination, fixing this line on logics. Yet, this was not in denial of the importance of the sentiment and values, but in recognition of their enormous power over reason, which often distorted and contested logics.

Fourth, CBD reminds us that culture is relative across time and space. The fact that different cultures and historic periods would fill in the definition of a good life with a different connotation is a fact of life, known since the work of the cultural geographer Strabo 25 B.C. While there might be a universal human moral, we do not have it clearly defined in one locality, neither the aggregate mean of values among world cultures is a constant over time. Cultures represent a colorful mix of group ethics of population clustered in space [82]. Therefore, CBD evokes here Plato's understanding of the case, where the true moral is the flame and local ethics are the reflections of it on the walls of local caves. Put differently, CBD claims that whenever the study of cultural impact on economic processes and choices is studied, the heterogeneity of every unique cultural value (i.e., the different level of affinity it enjoys in different societies) is an important source of bias, which is not a cognitive bias, but a cultural relativism moral bias. While cognitive bias deviates us individually from a known good target, the cultural relativity moral bias deviates us from knowing what a good target is and makes both our maximizing/optimizing and our satisficing $[28,68]$ behaviors differ across space. In Pierre Bourdieu's sense, the latter bias is called doxa [83]. Pierre Bourdieu is also the father of the notion of 
cultural capital which is central for CBD and helps us redefine Smith's 'Impartial' Spectator in a way adapted to the above reading of the literature.

\section{2. $C B D$ and the 'Impartial' Spectator}

The CBD rereading of the history of economic thought on culture and values culminates in the CBD definition of cultural capital. In a nutshell, the CBD paradigm can be outlined as follows. CBD defines culture as the set of attitudes and beliefs that describe the value system of the population that inhabits a certain geography. The possession of culture endows the society and the individual with power, which is termed cultural capital. CBD defines cultural capital in an evolutionary manner as a power with four dimensions, material and immaterial form, and timewise: inherent in nature (termed cultural heritage) and contemporaneously accumulated (termed living culture) [84,85]. In line with Bourdieu [83,86-88], the main take of CBD is that the endowment with cultural capital generates cultural bias on the socio-economic decision-making processes related to the carriers of certain cultural capital. These notions are the essential cornerstones for the re-reading of the existing literature on universal values through the CBD lens.

Based on the above, CBD suggests a new moral philosophy perspective devised in the realm of NCE for the study of the socio-economic world as an outcome from choosing in a culturally dependent manner among what is sometimes called 'all possible worlds' [89]. The CBD positive approach postulates that ideally all forms and types of worlds could be made possible [90], but all 'possible worlds' (enacted worlds) are man-made. What world a person or a society will find themselves in is only an outcome of (ultimately aggregated) individual choices [90]. The freedom of choice is in this context defined by CBD as the capability to dare, i.e., to choose under uncertainty what one's true internal natural intuition (internal preference) for moral choice suggests (as opposed to feeling constraint to subdue to the culturally imposed borders of what is virtuous to be chosen).

The use of the term freedom of choice here is inspired by Amartya Sen's notion of development as freedom and freedom as a set of capabilities to choose over certain options for choice [27,29]. Capability to dare however does not suggest that every person's free choice is more moral than the local culture, local moral or ethics of a group. A person may be driven strongly by one's own strong free-will, which might be very weakly fine-tuned with what is naturally beneficial to the outcome one seeks. This depends on the unique individual potential to use one's intuition. An example for a weak intuition is Hitler who was strongly driven to pursue his own free-will with which he believed he sought local development through the extermination of certain groups of people. The extermination of people does not however naturally increase the wellbeing of people, but instead naturally pulls the world in a world war against this inhumane aggression, and war is detrimental to human development. Therefore, we can objectively state that the free-will of Hitler was based not on universal values for human prosperity, but only on the weak intuition of the Nazi ethos.

This means also that in order to be truly beneficial, an individual's or group's ability to use intuition (free-will) needs to be finding the natural universal values truly conducive to the natural outcomes of interest (such as human prosperity and flourishing for example, [91]) instead of repeating the mistakes of history preserved in cultural memory (persistence) and path-dependence. In the narrower context of improving our moral, intuition is the innate passion that we feel towards an attitude believing it will have the best impact on an outcome of interest. Thus, our value system drives through our affinity (emotion) the construction of the 'best of all possible worlds' that we can achieve. It is worth noting here that the empirical analysis known today in economics is curbed within the boundaries of probabilities, which are based on the part of possible worlds already enacted as individual observations in time and space. This analysis can very weakly serve to identify the impact of new untried attitudes which have not accumulated enough frequency which is necessary for being recognized by the probabilistic analysis as existing in the reality factors for the outcomes of interest.

In specific, firstly, CBD defines cultural capital as the potential of local attitudes "to deeply influence socio-economic development". "Because of differences in historical conditions, cultural 
capital differs significantly between different locations. Local cultural capital shapes local people's values and attitudes that determine their choices and interactions" [84] (p. 4). In other words, cultural capital is endogenous and sticky in nature.

The original definition of cultural capital was coined by Pierre Bourdieu, who defined the notion as follows: "Cultural capital can exist in three forms: in the embodied state, i.e., in the form of long-lasting dispositions of the mind and body; in the objectified state, in the form of cultural goods (pictures, books, dictionaries, instruments, machines, etc.), which are the trace or realization of theories or critiques of these theories, problematics, etc.; and in the institutionalized state, a form of objectification which must be set apart because, as will be seen in the case of educational qualifications, it confers entirely original properties on the cultural capital which it is presumed to guarantee" [87] (p. 243). Additionally, Max Weber's definition (of social closure) comes very close to Bourdieu's understanding of cultural capital: "Closure on the basis of value-rational commitment to values is usual in groups sharing a common system of explicit religious belief" [92] (p. 44).

CBD claims that these two definitions merit to be merged in order the essence of cultural capital on aggregate level to be better understood. The CBD definition of cultural capital and the overall CBD paradigm are based on the idea of merging the meaning behind the above two definitions as explained in this paper. Namely, according to CBD, the locally accumulated cultural capital is embodied in the total stock of material and immaterial cultural goods at a given point in time and serves for between group distinction $[84,85])$

CBD starts from these foundations and argues further that cultural capital in a locality is a proto-institutional factor that influences economic performance through multiple channels. These channels include, firstly, the formation of other institutions. In the spirit of Tiebout's "Pure Theory of Local Expenditure", CBD states that culture is a proto-institution since it determines the formation and hierarchy of all other local institutions and this is a crucial feature of cultural capital's impact on local development [93].

Thus, secondly, cultural capital determines which of the locally created institutions will be formal and which informal (as defined by North $[47,48]$ ). If an attitude is widely supported in a culture and does not need formal regulation to be imposed on the local population's behavior, then this attitude serves as a foundation for the formation of the informal institutions. If an attitude is predominantly supported in a locality, but its enactment in human behavior needs to be controlled and regulated in order to be ensured throughout the whole society, then this attitude serves as a foundation for formal institutions in this locality. This is how the cultural capital creates a structural bias in Smith's 'Impartial' Spectator and generates the 'social energy' which constructs [94,95] the possible world [89].

The above allows to CBD to re-define Smith's 'Impartial' Spectator as the local mechanism through which the social energy for creating the possible world is preserved across generations. This CBD's 'Impartial' Spectator is elsewhere termed as the mechanism of local cultural gravity [96]. Cultural gravity pulls a mass of human capital towards a shared local 'moral' code of choosing. This mechanism operates on the basis of Smith's sympathy. When an individual chooses according to the local cultural moral this creates the benefits of sympathy within and for this individual. The individual is satisfied since their choice matches with their own individual's perceptions of what should be natural universally moral and their actions are judged (agreeably for her/him) as properly moral by the local society. That is how and why people sharing common culture shape a society [82].

The summary of the cornerstones of the CBD paradigm, outlined above, and the CBD reinterpretation of Smith's Impartial Spectator are necessary to be comprehended in order to allow the understanding of the proposed CBD approach for answering Smith's first sub-question in moral philosophy, namely: which virtue is really virtuous (i.e., a naturally true universal value). This contribution by CBD to the current state-of-the-art of NCE is elaborated in detail in the next sub-section of this study. 


\section{Main Principles of the CBD Value-Free Analysis of Values}

Ultimately, CBD seeks to analyze the objective effect of an attitude on the output without implying any qualitative judgement whether this is a good or a bad (virtuous or not virtuous) outcome i.e., in a value-free manner. Moreover, CBD aims to offer a roadmap for answering both the first Adam Smith's question about moral philosophy (whether a value is universally virtuous), and also his second question, regarding the systematic internal mechanisms and complexities of this impact. CBD does so through a positive methodology and with a different rationale than what has been done so far.

Addressing the first question, the CBD value-free study of values leads us to first objectively identify whether a value/attitude is universally-contributive to certain outcomes of interest, without involving subjective pre-determined classifications or prescriptions of what should be thought as 'virtuous'. Here, the CBD approach suggests focusing the analysis on a positive exploration of what are the objective observed consequences of certain values.

Addressing the second question, the CBD approach suggests accounting for the complexity of culture and the non-linearity of its impact [97]. CBD classifies a value's universality based on positively documented trans-geographical and trans-cultural impact of this value on certain outcomes of interest. CBD distinguishes between a true universal/moral value and a culturally biased universal value. The distinction between the two types of universal values is based on the objective universality of the impact from the value with regards to the same outcome across space as opposed to presence of local cultural bias (expressed in heterogeneity of the impact across space). Put differently, the CBD addresses the second question by finding out in a positive manner whether a certain value behaves as: (i) part of a truly universal 'Impartial' Spectator (of Adam Smith's original type); or (ii) a value that has (a) a varying significance across time and space and also (b) only a partial, in terms of weak, Culturally Biased Spectator (i.e., ultimately boundedly partial 'Impartial' Spectators (due to doxa, as defined in the previous section)). Thus, the $\mathrm{CBD}$ proposed approach of value-free analysis of values entails a procedure composed of three clear cut methodological steps, as detailed below.

\subsection{When Is a Value Universal?}

CBD proposes the positive study of values to start with the clear acknowledgement of the Cartesian doubt, i.e., the limitation of the mind in knowing the absolute truth even based on induction. CBD recognizes that the natural moral cannot be readily known by human deduction or induction, and yet, CBD proposes a positive study of values, aiming to understand: (i) whether they are potentially of universal benefit with regard to particular outcome of interest and (ii) if so-how much deviation (cultural bias) exists locally with regards to these universal values in the current world. Put differently, CBD proposes to study positively the universality of the impact from values through empirical methods regarding particular outcomes. This positive approach purges the value judgementalism in the analysis of values by basing the classification on observed outcomes.

Namely, the first step of the proposed CBD approach to value-free analysis of values is consistent as method with what is done so far in quantitative studies in cultural economics, but the CBD interpretation of the results is from a different perspective. It still entails identifying a measure or proxy for a certain cultural value that varies across individuals or places, and then testing whether this value-related variable exhibits statistical significance for the outcome of interest $[23,24]$. However, it judges the universal 'virtuousness' of the value based on the statistical significance it can exhibit. Clearly, this testing requires precise model and quantitative method, implemented at the presence of individual and space related fixed effects and relevant controls and other explanatory variables that fully specify the model.

The above first step of the CBD approach is in line with Adam Smith's suggestion that universal values are a natural global tendency of all 'Impartial' Spectators', who indifferent of their subjective and culturally relative bias are generally converging towards a common natural tendency worldwide (see Glick [98] on cultural relativity and differences between culture and morality from anthropological perspective and Littlewood [99] for an extensive literature review on the matter). Smith's claim that a 
worldwide predominant value is universal however is treated by $\mathrm{CBD}$ as in essence a deterministic claim. Instead, CBD first positively tests whether the affinity to the value produces the desired outcome of interest and only then classifies this value as universal. Thus, it is not the presence of affinity but the outcome of this affinity that $\mathrm{CBD}$ uses to define the universality of the value in a value-free manner.

\subsection{Aristotelian Kuznets Curve}

Aristotle's and Plato's view on values are sometimes considered as opposing since Aristotle's view suggests that some middle enacted level of an attitude is best (virtuous), while Plato generally suggests that nothing practiced is as good as the real true best (virtue) [100]. Yet, CBD interprets these two stands as simply alternative aspects of virtue. Aristotle's take regards the amount of affinity (passion) and its eventual turning point above which the effect of the value of the outcome changes sign after a certain increase in amount of affinity to this value. Plato's take on virtue, instead, is embraced by $\mathrm{CBD}$ from the perspective of its meaning for regional cultural relativity, namely: the local natural moral can be seen as always deviating from the natural ideal mean due to local cultural biases and path-dependencies in culture.

Kuznets [101,102] demonstrated that the concentration of people in cities had first a positive, then a negative association with certain regional development aspects such as inequality. Similar relationship of urbanization with pollution was termed the environmental Kuznets curve [103,104]. CBD reinterprets this in Aristotelian golden mean sense, as the 'goodness' of the value to be in the city being first associated with a positive outcome, yet, with the increase in affinity to this value, an inflection point in the impact occurs, and its impact becomes positive (entailing many complex economic reasons for this switch of sign).

Therefore, CBD proposes that at a second step, after identifying the universality of a certain value, the analysis of its impact should go beyond asking whether an impact exists universally and should disentangle how exactly this impact is generated. Namely, CBD points to the importance of acknowledging the Aristotelian notion of the 'golden mean' of a value. Aristotle, whom Smith largely follows in his dwelling on virtue, suggests that a virtue is not an extreme but a well-measured optimally balanced point between two extremes of affinity to an attitude. For example, too much affinity to the attitude that good humour is important may result in a phoney clownish behavior, and too little affinity to this attitude may result into low spiritedness.

Thus, the positive approach proposed by CBD coins here the notion of Aristotelian Kuznets Curve which can be used to conduct the empirical analysis of the impact from a value in terms of the existence of an inflection point. Such an inflection point will document a non-linearity in the impact from this value (i.e., a form of Kuznets curve type of relationship between the increase in affinity to an attitude (how much virtuous a virtue is perceived) and its impact on the outcome of interest). This Kuznets curve relationship should be thought of in absolute terms as a nonlinearity of the impact at the presence of a linear increase in the input. Thus, the presence of an inflection point is interesting in itself, indifferent if it switches from positive to negative impact or vice versa. This is part of the value-free rationale proposed here by CBD.

If such an inflection point is found to exist, then Amartya Sen's claim that freedom of capabilities is a universal value will be positively empirically confirmed. Namely, a Kuznets curve of this kind will signify that too much of any virtuous/'good thing' (too much of affinity to an universal value, may become, after a certain level of affinity, less conducive to the outcome of interest (i.a. there are prominent contributions to growth theory, showing that too much investment in R\&D becomes negatively impacting the economic growth process [105]). Therefore, when the inflection point is reached, people should have the freedom to switch their order of preferences and opt out from further increases in their affinity to this value if they want to optimize the cultural value input and to maximize the outcome of interest.

Put differently, it is crucial that decision makers have the freedom to constantly update themselves on whether their level of affinity to a certain attitude is currently below, at or above the inflection point 
of the Aristotelian Kuznets curve and to change their order of preferences accordingly, so that their overall utility is indeed maximized through their choice. Yet, the existence of an Aristotelian Kuznets curve in the relationship between the amount of an affinity to a value and the amount of a certain outcome of interest is an empirical question.

\subsection{Platonian Cultural Bias: Subjectivity and Relativity of the 'Impartial' Spectator}

Adam Smith himself noted that the 'Impartial' Spectator is prone to individual subjectivity and cultural relativity biases due to customs and social proximity (TMS, Part I, Chapter I-V; Part V, Chapter I). CBD agrees with this, by understanding it from Plato's point of view that the true moral is an unknown ideal state of calibration of the affinity to certain values (a view that has been pointed out also in related research $[99,106]$. Local ethics represent only 'reflections from the flame' of this ideal on the local 'cave' of a particular time and space. Thus, CBD states that local cultural capital creates local culturally biased 'morals' which have been transmitted across generations through the persistence of group ethics.

CBD therefore proposes as a third step the analysis of universal values to pass through the empirical cleaning of subjectivity and positive documentation of its geographic relativity. In particular, CBD suggests that the individual subjectivity of values can be treated as individual uniqueness (see Shackle [36]) and can be cured empirically through the use of individual fixed effects. CBD has also been flagging elsewhere (see for instance [69]) the danger of 'throwing the baby with the water', since an under-specification of an empirical model may result due to the omission of the cultural factor and simple use of individual fixed effects. Use of fixed effects without presence of cultural explanatory variables results in inability to analyze the cultural effect on individual choice. Here, however, we recommend use of individual fixed effects in the presence of cultural explanatory variables).

Meanwhile, the cultural relativity of values and moral systems can be understood and handled in the analysis as a local (ethical/cultural) bias over the 'fellow-feeling' which dictates the 'Impartial' Spectators 'sentimental' reasoning (for some recent contributions on the role of feelings/emotions in socio-economic behavior, see Borowecki [107] from an economic perspective, and Nussbaum [8] from a philosophical perspective). This bias is sometimes termed in the economic literature as 'home bias' [108-110]. This cultural relativity bias has in its roots the local cultural capital and it creates nestedness of the individual observations in local cultural groups. This nestedness has to be empirically modelled accordingly in order to cure the Platonian cultural bias from identifying the impact of a value. The use of hierarchical modelling or other related methods that stochastically account for both the individual and local effects in the data are suggested to cure the Platonian subjective and cultural relativity.

Figure 1 provides a synthesis of the above proposed three steps. It depicts the logic tree behind the three steps that the CBD value-free analysis of values suggests and sums up the main rationale for each step. Implementing the three steps of the CBD value-free analysis of values can help determine whether a value has a universal socio-economic significance; whether there is some limit to its exploitation (if there is an inflection point shaping an Aristotelian Kuznets curve); and whether it is subject to cultural biases that can make the transferability of interventions with regard to this value sensitive to the context in which they are implemented (pointing precisely analytically to what structural level drives the effect in the economic system). 


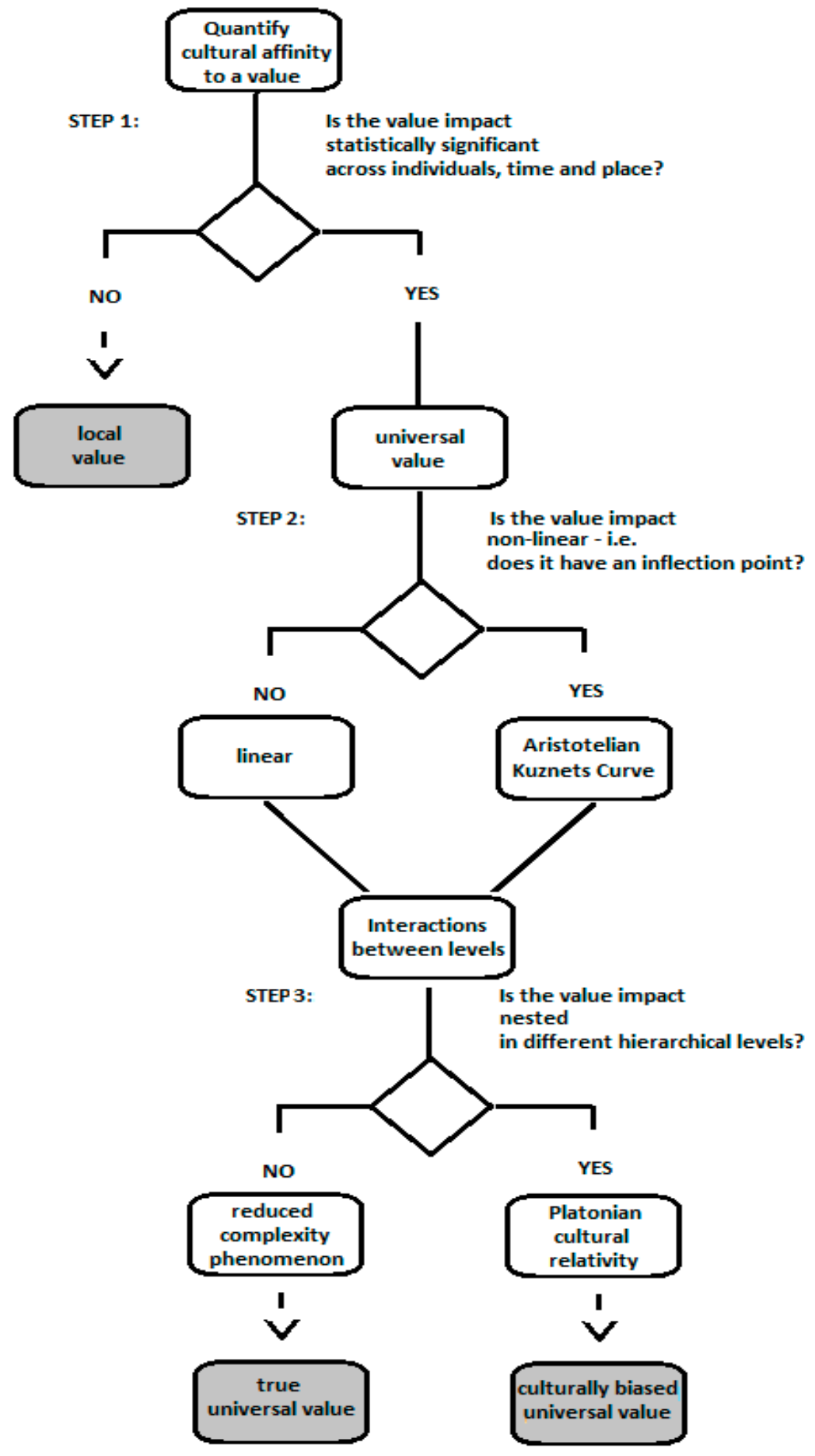

Figure 1. The CBD Value-free Analysis of Values—Logic Tree Diagram. Note: The figure shows the essence of each logical step in the CBD value-free analysis of values, respectively: (i) Step 1-identifying whether a value is universal or local in terms of its impact; (ii) Step 2-identifying nonlinearities in the impact from the value, or the presence of what is called the Aristotelian Kuznets Curve; (iii) Step 3 -exploring the complexities of the impact from the value in terms of the individual and local levels that shape the Platonian cultural relativity of values. 


\section{Conclusions}

The current study sought to provide a methodological road-map for implementing a value-free analysis of values. Providing such a road-map can answer the needs for merging modern moral philosophy, political economy and economic analysis and planning, identified by major figures in the field (such as Amartya Sen and Martha Nussbaum [3-9,26-29]).

The current paper provided its proposed roadmap to value-free analysis of values, basing it on the rereading of three classical notions related to values (the Aristotelian golden mean; Platonian cave of cultural relativity and perception; and Adam Smith's 'Impartial' Spectator), which were revisited and reinterpreted from the point of view of the novel research paradigm of CBD.

The CBD approach to the value-free analysis of values follows the overarching principle that the 'goodness' or 'badness' of a value can be known only positively, by observing the generalizable effect from high affinity to this value to certain socio-economic outcome of interest across individuals, time and space. The CBD value-free analysis of values proposes in particular three steps of analysis: (i) identifying whether there is a universal effect from the value; (ii) delving into the non-linearities of this effect through what CBD calls the Aristotelian Kuznets Curve and (iii) delving further in the structural levels at which this effect is generated (individual and local), thus accounting for Plantonian relativity of values. This CBD approach allows the empirical positive study of the cultural effect in its complexity. It avoids determinism but allows us to achieve higher world view awareness as well as precision (than what the literature so far has demonstrated) in the observation and monitoring of the effect from culture with better understanding as to why we observe that culture matters and how this effect is likely to evolve over time and space.

The value-free analysis of values enables an economic analysis which starts from the standard value-free empirical identification of an effect from cultural values, but it takes the analysis two steps further from the fallacy of misplaced concreteness [12]. This fallacy implies that empirical work may identify an effect from a certain factor in a particular moment of time, yet this may not be evidence for the presence of a deterministic economic law about this relationship. First, the CBD approach can precisely capture an important part of the nonlinearity of the impact from values. Namely, it can signal when too much of a good thing can start turning the effect in reverse $[105,111]$. Second, it accounts for the complexity (in line among others with modern DSG and Agent Based modelling rationales) and the understanding that the macro effects have micro-foundations. Nowadays, empirical methods can allow for quantifying and precisely observing these dependencies and CBD points to the availability of these tools and advices for their application when the study of values is at stake.

Finally, the proposed CBD approach to value-free analysis of values is not only a methodological rationale for how values should be quantified and positively studies, but it also offers a world view for path cutting through the existing plethora of contributions on values, showing how the value-free analysis of values can accommodate for many essential classical premises about the good life (stemming from the time of Plato and Aristotle [112]) and the fundaments of Adam Smith's theory of moral sentiments.

Last, but not least, the CBD approach to value-free analysis of values, precipitates the common red line that unites the wealth of seemingly loosely related quantitative studies in the field of political Economy, NCE and NIE. CBD points to the theoretical underpinnings that unite and consolidate these studies around a logical common methodological approach. It allows a more efficient comparison and theoretical synthesis between studies on values that may use different quantitative proxies for culture and values in their empirical operationalization, but can become comparable on the basis of applying the common CBD paradigm and its value free research approach to values as a fundament of the socio-economic process. This elevates the modern empirical cultural economics to a next level of conceptual, theoretical and analytical horizons.

Funding: This research received no external funding.

Conflicts of Interest: The author declares no conflict of interest. 


\section{References}

1. Baumeister, R.; Leary, M. Writing Narrative Literature Reviews. Rev. Gen. Psychol. 1997, 1, 311-320. [CrossRef]

2. Tranfield, D.; Denyer, D.; Smart, P. Towards a Methodology for Developing Evidence-Informed Management Knowledge by Means of Systematic Review. Br. J. Manag. 2003, 14, 207-222. [CrossRef]

3. Sen, A. Gender Inequality and Theories of Justice. In Women, Culture, and Development; Nussbaum, M.C., Glover, J., Eds.; Clarendon Press: Oxford, UK, 1995; pp. 259-273.

4. Sen, A. On Ethics and Economics; Blackwell: Oxford, UK, 1987.

5. Nussbaum, M.C. Philosophy and Economics in the Capabilities Approach: An Essential Dialogue. J. Hum. Dev. Capab. 2015, 16, 1-14. [CrossRef]

6. Nussbaum, M.C. Economics Still Needs Philosophy. Rev. Soc. Econ. 2016, 74, 229-247. [CrossRef]

7. Nussbaum, M.C. Morality and Emotions. Routledge Encycl. Philos. 2018. [CrossRef]

8. Nussbaum, M. Upheavals of Thought: The Intelligence of Emotions; Cambridge University Press: Cambridge, UK, 2001.

9. Nussbaum, M.; Sen, A. The Quality of Life; Calrendon Press: New York, NY, USA, 1993.

10. Smith, A. The Theory of Moral Sentiments; Oxford University Press: Oxford, UK, 1759.

11. Khalil, E.L. Adam Smith and Three Theories of Altruism. Rech. Econ. Louvain 2001, 67, 421-435. [CrossRef]

12. Robbins, L. An Essay on the Nature and Significance of Economic Science; Macmillan \&, Co.: London, UK, 1932.

13. Heilbroner, R.L. Economics as a "Value-Free" Science. Soc. Res. 1973, 40, 129-143.

14. Putnam, H.; Walsh, V. The End of Value-Free Economics; Routledge: London, UK, 2012.

15. Klappholz, K. Value Judgments and Economics. Br. J. Philos. Sci. 1964, 15, 97-114. [CrossRef]

16. Sinha, A. Theories of Value from Adam Smith to Piero Sraffa; Taylor \& Francis: London, UK, 2018.

17. Simon, H. A behavioral model of rational choice. Q. J. Econ. 1955, 69, 99-118. [CrossRef]

18. Scitovsky, T. The Joyless Economy; Oxford University Press: New York, NY, USA, 1992.

19. Kahneman, D. Thinking, Fast and Slow; Macmillan: London, UK, 2011.

20. Adkisson, R.V. Quantifying Culture: Problems and Promises. J. Econ. Issues 2014, 48, 89-108. [CrossRef]

21. Tubadji, A.; Nijkamp, P. Cultural Corridors: An Analysis of Persistence in Impacts on Local Development-A Neo-Weberian Perspective on South-East Europe. J. Econ. Issues 2018, 52, 173-204. [CrossRef]

22. Alesina, A.; Perotti, R. The Political Economy of Growth: A Critical Survey of the Recent Literature. World Bank Econ. Rev. 1994, 8, 351-371. [CrossRef]

23. Guiso, L.; Sapienza, P.; Zingales, L. Does Culture Affinity Economic Outcomes? J. Econ. Perspect. 2006, 20, 23-48. [CrossRef]

24. Alesina, A.; Giuliano, P. Culture and Institutions. J. Econ. Lit. 2015, 53, 898-944. [CrossRef]

25. Alesina, A.; Miano, A.; Stantcheva, S. The Polarization of Reality. AEA Pap. Proc. 2020, 110, $324-328$. [CrossRef]

26. Sen, A. The Idea of Justice; Harvard University Press: Cambridge, MA, USA, 2009.

27. Sen, A.K. Development as Freedom; Anchor Books: Oxford, UK, 1999.

28. Sen, A. Rational Behaviour. In Utility and Probability; Palgrave Macmillan: London, UK, 1990; pp. $198-216$.

29. Sen, A. Freedom, Capabilities and Public Action: A Response. Politeia 1996, 12, 107-125.

30. Schwartz, S.H. Are There Universal Aspects in the Structure and Contents of Human Values? J. Soc. Issues 1994, 50, 19-45. [CrossRef]

31. Schwartz, S.H. Basic Human Values: Theory, Measurement, and Applications. Rev. Française Sociol. 2006, 47, 929-968. [CrossRef]

32. Schwartz, S.H.; Bilsky, W. Toward a Universal Psychological Structure of Human Values. J. Personal. Soc. Psychol. 1987, 53, 550-562. [CrossRef]

33. Orléan, A. The Empire of Value: A New Foundation for Economics; MIT Press: Cambridge, MA, USA, 2014.

34. Persson, B.N.; Kajonius, P.J. Empathy and Universal Values Explicated by the Empathy-Altruism Hypothesis. J. Soc. Psychol. 2016, 156, 610-619. [CrossRef]

35. Anderson, E. Value in Ethics and Economics; Harvard University Press: Cambridge, MA, USA, 1993.

36. Shackle, G.L.S. Time and Thought. Br. J. Philos. Sci. 1959, 9, 285-298. [CrossRef]

37. Fleischacker, S. Sympathy in Hume and Smith. In Intersubjectivity and Objectivity in Husserl and Adam Smith; Fricke, C., Føllesdal, D., Eds.; Ontos Verlag: Frankfurt, Germany, 2012. 
38. Hausman, D.M. The Impossibility of Interpersonal Utility Comparisons. Mind 1995, 104, 473-490. [CrossRef]

39. Martinez-Alier, J.; Munda, G.; O'Neill, J. Weak Comparability of Values as a Foundation for Ecological Economics. Ecol. Econ. 1998, 26, 277-286. [CrossRef]

40. Mongin, P. Value Judgments and Value Neutrality in Economics. Economica 2006, 73, 257-286. [CrossRef]

41. Foucault, M. Madness and Civilization: A History of Insanity in the Age of Reason, abridged English ed.; Vintage: New York, NY, USA, 1965.

42. Derrida, J. Of Grammatology; The Johns Hopkins University Press: Baltimore, MA, USA, 1967.

43. Philo, C. A ‘New Foucault' with Lively Implications-Or 'the Crawfish Advances Sideways'. Trans. Inst. Br. Geogr. 2012, 37, 496-514. [CrossRef]

44. Cooter, R.; Rappoport, P. Were the Ordinalists Wrong About Welfare Economics? J. Econ. Lit. 1984, 22, 507-530.

45. Samuelson, P. Abram Bergson, Economist April 21, 1914-April 23. Econ. J. 2005, 115, F130-F133. [CrossRef]

46. Pugno, M. Scitovsky's The Joyless Economy and the Economics of Happiness. Eur. J. Hist. Econ. Thought 2014, 21, 278-303. [CrossRef]

47. North, D.C. Institutions, Institutional Change and Economic Performance; Cambridge University Press: Cambridge, UK, 1990.

48. North, D.C. Institutions and Their Consequences for Economic Performance. In The Limits of Rationality; Schweers Cook, K., Levi, M., Eds.; University of Chicago Press: Chicago, IL, USA, 1990; pp. 383-401.

49. North, D.C. Institutions. J. Econ. Perspect. 1991, 5, 97-112. [CrossRef]

50. Faundez, J. Douglass North's Theory of Institutions: Lessons for Law and Development. Hague J. Rule Law 2016, 8, 373-419. [CrossRef]

51. Kahneman, D.; Tversky, A. Prospect Theory: An Analysis of Decision under Risk. Econometrica 1979, 47, 263-292. [CrossRef]

52. Shleifer, A. Psychologists at the Gate: A Review of Daniel Kahneman's Thinking, Fast and Slow. J. Econ. Lit. 2012, 50, 1080-1091. [CrossRef]

53. Knack, S.; Keefer, P. Does Social Capital Have an Economic Payoff? A Cross-Country Investigation. Q. J. Econ. 1997, 112, 1251-1288. [CrossRef]

54. Glaeser, E.L.; Laibson, D.I.; Scheinkman, J.A.; Soutter, C.L. Measuring Trust. Q. J. Econ. 2000, 115, 811-846. [CrossRef]

55. Guiso, L.; Sapienza, P.; Zingales, L. People's Opium? Religion and Economic Attitudes. J. Monet. Econ. 2003, 50, 225-282. [CrossRef]

56. Ottaviano, G.; Peri, G. The Economic Value of Cultural Diversity: Evidence from US Cities. J. Econ. Geogr. 2006, 6, 9-44. [CrossRef]

57. Ottaviano, G.; Peri, G. Cities and Cultures. J. Urban Econ. 2005, 58, 304-337. [CrossRef]

58. Tabellini, G. Culture and Institutions: Economic Development in the Regions of Europe. J. Eur. Econ. Assoc. 2010, 8, 677-716. [CrossRef]

59. Beugelsdijk, S.; Klasing, M.J. Measuring Value Diversity within Countries. In Social Economics: Current and Emerging Avenues; Costa-Font, J., Macis, M., Eds.; MIT Press: Cambridge, MA, USA, 2017.

60. Manzini, P.; Mariotti, M. Competing for Attention: Is the Showiest Also the Best? Econ. J. 2017, 128, 827-844. [CrossRef]

61. Hahn, F. Culture, Gegraphy and Institutins: Empirical Evidence from Small-Scale Banking. Econ. J. 2014, 124, 859-886. [CrossRef]

62. Alkire, S. Valuing Freedoms: Sen's Capability Approach and Poverty Reduction; Oxford University Press: New York, NY, USA, 2004.

63. Pettit, P. Capability and Freedom: A Defence of Sen. Econ. Philos. 2001, 17, 1-20. [CrossRef]

64. Kant, I. Critique of Pure Reason; Cambridge University Press: Cambridge, UK; New York, NY, USA, 1998.

65. Mahoney, M.J.; Demonbreun, B.G. Psychology of the Scientist: An Evaluative Review. Soc. Stud. Sci. 1979, 9, 349-375. [CrossRef]

66. Tannoch-Bland, J. From Aperspectival Objectivity to Strong Objectivity: The Quest for Moral Objectivity. Hypatia 1997, 12, 155-178. [CrossRef]

67. Thaler, R.; Sunstein, C. Nudge: Improving Decisions about Health, Wealth, and Happiness; Yale University Press: New Haven, CT, USA, 2008.

68. Todd, P.M.; Gigerenzer, G. Bounding Rationality to the World. J. Econ. Psychol. 2003, 24, 143-165. [CrossRef] 
69. Tubadji, A. Was Weber Right? The Cultural Capital Roots of Economic Growth. Int. J. Manpow. 2014, 35, 56-88. [CrossRef]

70. Acemoglu, D.; Robinson, J. The Role of Institutions in Growth and Development. Rev. Econ. Inst. 2010, 1, 1-33. [CrossRef]

71. Weber, M. The Protestant Ethic and the Spirit of Capitalism; Unwin Hyman: London, UK; Boston, MA, USA, 1905.

72. Piketty, T. Capital and Ideology; Harvard University Press: Cambridge, MA, USA, 2020.

73. Piketty, T.; Goldhammer, A. Capital in the 21 Century; Goldhammer, A., Translator; Belknap Press: Cambridge, MA, USA, 2014.

74. Esteban, J.; Ray, D. On the Measurement of Polarization. Econometrica 1994, 62, 819-851. [CrossRef]

75. Hirschman, A.; Rothschild, M. The changing tolerance for income inequality in the course of economic development: With a mathematical appendix. Q. J. Econ. 1973, 87, 544-566. [CrossRef]

76. Bénabou, R.; Tirole, J. Belief in a Just World and Redistributive Politics. Q. J. Econ. 2006, 121, $699-746$. [CrossRef]

77. Benabou, R.; Tirole, J. Over My Dead Body: Bargaining and the Price of Dignity. Am. Econ. Rev. 2009, 99, 459-465. [CrossRef]

78. Bénabou, R.; Tirole, J. Identity, Morals, and Taboos: Beliefs as Assets. Q. J. Econ. 2011, 126, 805-855. [CrossRef] [PubMed]

79. Bénabou, R.; Tirole, J. Mindful Economics: The Production, Consumption, and Value of Beliefs. J. Econ. Perspect. 2016, 30, 141-164. [CrossRef]

80. Edwards, J.; Pelle, S. Capabilities for the Miserable, Happiness for the Satisfied. J. Hist. Econ. Thought 2011, 33, 335-355. [CrossRef]

81. Spinoza, B. Ethics; Curley, E., Translator; Penguin: London, UK, 1996.

82. Akerlof, G.A. Social Distance and Social Decisions. Econometrica 1997, 65, 1005. [CrossRef]

83. Bourdieu, P. Outline of a Theory of Practice; Cambridge University Press: Cambridge, UK, 1977.

84. Tubadji, A. Culture-Based Development-Culture and Institutions: Economic Development in the Regions of Europe. Int. J. Soc. Syst. Sci. 2013, 5, 355. [CrossRef]

85. Tubadji, A. Culture-Based Development: Empirical Evidence for Germany. Int. J. Soc. Econ. 2012, 39, 690-703. [CrossRef]

86. Bourdieu, P. Masculine Domination; Stanford University Press: Redwood City, CA, USA, 2002.

87. Bourdieu, P. Forms of Capital. In Handbook of Theory and Research for the Sociology of Education; Richardson, J., Ed.; Greenwood: New York, NY, USA, 1986.

88. Bourdieu, P. Distinction: A Social Critique of the Judgement of Taste; Harvard University Press: Cambridge, MA, USA, 1984.

89. Leibniz, G.W. Theodicy: Essays on the Goodness of God, the Freedom of Man, and the Origin of Evil; Routledge \& K. Paul: London, UK, 1952.

90. Richter, M.; Rubinstein, A. Back to Fundamentals: Equilibrium in Abstract Economies. Am. Econ. Rev. 2015, 105, 2570-2594. [CrossRef]

91. Park, N.; Peterson, C.; Ruch, W. Orientations to Happiness and Life Satisfaction in Twenty-Seven Nations. J. Posit. Psychol. 2009, 4, 273-279. [CrossRef]

92. Weber, M. Economy and Society; University of California Press: Berkeley, CA, USA, 1922.

93. Tubadji, A.; Angelis, V.; Nijkamp, P. Endogenous Intangible Resources and Their Place in the Institutional Hierarchy. Rev. Reg. Res. 2015, 36, 1-28. [CrossRef]

94. Janowski, B. On Distances as a Factor for Cultural Development. Pozn. Bogucki Wydaw. Nauk. 2013, 61, 680.

95. Gogerty, N. The Nature of Value: How to Invest in the Adaptive Economy; Columbia Business School Publishing: New York, NY, USA, 2014.

96. Tubadji, A.; Nijkamp, P. Cultural Gravity Effects among Migrants: A Comparative Analysis of the EU15. Econ. Geogr. 2015, 91, 343-380. [CrossRef]

97. Nijkamp, P. Ceteris Paribus, Spatial Complexity and Spatial Equilibrium. Reg. Sci. Urban Econ. 2007, 37, 509-516. [CrossRef]

98. Glick, L.B. Culture and Morality: The Relativity of Values in Anthropology. Elvin Hatch. Am. Ethnol. 1984, 11, 198-199. [CrossRef]

99. Littlewood, R.A. Culture and Morality: The Relativity of Values in Anthropology. Elvin Hatch. J. Anthr. Res. 1984, 40, 335-336. [CrossRef] 
100. Van Staveren, I. The Values of Economics: An Aristotelian Perspective; Routledge: London, UK, 2001.

101. Kuznets, S. Economic Growth and Income Inequality. Am. Econ. Rev. 2019, 1, 25-37. [CrossRef]

102. Kuznets, S. Quantitative Aspects of the Economic Growth of Nations: VIII. Distribution of Income by Size. Econ. Dev. Cult. Chang. 1963, 11, 1-80. [CrossRef]

103. Grossman, G.M.; Krueger, A.B. Economic Growth and the Environment. Q. J. Econ. 1995, 110, $353-377$. [CrossRef]

104. Grossman, G.; Krueger, A. The Inverted-U: What Does It Mean? Environ. Dev. Econ. 1996, 1, $119-122$. [CrossRef]

105. Strulik, H. Too Much of a Good Thing? The Quantitative Economics of R\&D-Driven Growth Revisited. Scand. J. Econ. 2007, 109, 369-386.

106. Qizilbash, M. Development, Common Foes and Shared Values. Rev. Political Econ. 2002, 14, 463-480. [CrossRef]

107. Borowiecki, K.J. How Are You, My Dearest Mozart? Well-Being and Creativity of Three Famous Composers Based on Their Letters. Rev. Econ. Stat. 2017, 99, 591-605. [CrossRef]

108. Obstfeld, M.; Rogoff, K. The Six Major Puzzles in International Macroeconomics: Is There a Common Cause. In NBER Macroeconomics Annual; Bernanke, B., Rogoff, K., Eds.; MIT Press: Cambridge, MA, USA, 2003.

109. Bernstein, S.; Lerner, J.; Schoar, A. The Investment Strategies of Sovereign Wealth Funds. J. Econ. Perspect. 2013, 27, 219-238. [CrossRef]

110. Morrison, P.S.; Weckroth, M. Human Values, Subjective Well-Being and the Metropolitan Region. Reg. Stud. 2018, 52, 325-337. [CrossRef]

111. Beyerlein, K.; Hipp, J.R.; Alba, R.D.; Rumbaut, R.G.; Marotz, K. Social Capital, Too Much of a Good Thing? American Religious Traditions and Community Crime. Soc. Forces 2005, 84, 995-1013. [CrossRef]

112. Aristotle. Nicomachean Ethics; Broadie, S.; Rowe, C., Translators; Oxford University Press: Oxford, UK, 2002.

Publisher's Note: MDPI stays neutral with regard to jurisdictional claims in published maps and institutional affiliations. 